\title{
A Methodological Survey for Fire Detection in Camera Surveillance
}

\author{
Rohini Jadhav ${ }^{1}$, P. D. Lambhate ${ }^{2}$ \\ ${ }^{1}$ M.E (Computer) Department of Computer Engineering, Jayawantrao Sawant College of Engineering, Pune, India. \\ Savitribai Phule Pune University, Pune, Maharashtra, India -411007 \\ ${ }^{2}$ Professor (Computer) Department of Computer Engineering, Jayawantrao Sawant College of Engineering, Pune, India. \\ Savitribai Phule Pune University, Pune, Maharashtra, India -411007
}

\begin{abstract}
One of the leading hazards affecting everyday life around the world might be smoke, fire and flame. Smoke detectors are widely used for detecting fire and raised alarm saving people life. However, faulty smoke detectors cause false alarm resulting from smoke and fire. In addition, smoke detector fails to detect fires in large spaces including outdoor spaces, auditorium, and warehouses which are not reliable. With rapid development traditional fire detection system has been replaced by vision based system. Researchers got attracted towards the detection method which is visually based. Now a day's to monitor on real time activities surveillance cameras are placed in all hazardous places. The advantages of real time fire detection using surveillance cameras are summarized as following points: first, intuitive techniques. Second, no delay time in real time detection as high transmission and induction. Third, surveillance camera having larger detection range and is confined to remote areas. Fourth, real time detection allows recording and saving the activity which helps us for future verification of fire occurrence.
\end{abstract}

Keywords: Fuzzy logic, Video surveillance, Fire Detection, frame differencing, morphology.

\section{Introduction}

Since the fire causes serious disasters, fire detection has been an important study to protect human life. The number of large high buildings is increasing, with the development of economy. If fire happens in these places, and has a bad social impact, major property damage and heavy casualties will be easily caused. So fire should get detected in less time for extinguish and evaluation. In high buildings, large rooms and outdoor places, traditional fire detectors can hardly detect fire characteristic parameters like smoke, temperature, vapor and flame in the early time, and ultimately cannot meet the demand of early fire detection in such place.

The basic idea of fire detection using video surveillance is come from the fact that other methods of fire detection like sensors and all always need high deployment and maintenance cost. The proposed fire detection algorithm processes visual information acquired through static camera that lets us incorporate the techniques to CCTV surveillance system, and therefore does not require an additional expanses on conventional fire sensors and it is always having proneness of producing wrong alerts. For that it is good to analyze different fire feature as done in[4]. There are different algorithms for concluding output like SVM, MES, etc, but they have some limitations those are overcome by fuzzy logic algorithm [5]. So proposed system put forwards an idea for detection of fire by using color, motion and shape which is powered with fuzzy logic for providing more accuracy. The main purpose of this proposed system is to minimize the false positivism of the fire detection and to increase the efficiency of the model of fire detection for indoor and outdoor scenes.

For further proceeding of this paper section II is dedicated for related work, and section III is for conclusion.

\section{Related Work}

[1] A real-time fire detectors have been developed which combines foreground information and color information. Due to some changes in background or object motion into the scene, foreground objects are detected by removing background. A set of sample images have been collected and segmented into fire and non-fire regions. Then by analyzing each pixel in the fire blobs, the value of red color channel is greater than green color channel and value of green color channel is greater than blue color channel. Also, in fire color red channel saturation is high. These rules are used to determine color information of fire. The detected foreground object and color information are combined and output is analyzed in consecutive frames. This real time detector processes $30 \mathrm{fps}$ with image size 176x144. System performance is excellent because it requires less memory and less cost as it stores value of $x$ pixel at time $t$ and $t+1$. But this system fails when it recognize person with red cloths or red color object as fire just because output is based on only color information.

[2] Optical flow and foreground image accumulation techniques are used to detect smoke and flame in real-time. There are two cases for wrong fire detection, first is object with fire like reddish color and second might be that the background with illusion of burning fire, solar reflections, and artificial light. So to overcome this drawback, this paper used the key to distinguish between smoke and smokecolored and flame and flame-colored objects is their physical movement. To calculate movement firstly foreground image segmentation is done using frame differential method. After that flame color model and smoke color model are created using HIS color model.RGB color model has less computation complexity but HIS color model is often adapted, because it is suitable for providing more people oriented way of describing the colors. Then weighted stack 


\section{International Journal of Science and Research (IJSR) \\ ISSN (Online): 2319-7064 \\ Index Copernicus Value (2013): 6.14 | Impact Factor (2014): 5.611}

is maintained to calculate foreground images of consecutive image frames, so bigger the pixel value if more times the same region of foreground images appears in consecutive frames. The pixel values will decrease to zero, if the corresponding region no longer appears in foreground images. Foreground accumulation of flame is calculated differently for flame and smoke. Then block image processing technique is used to flame motion feature recognition. In that each image is divided into $8 \times 8$ resolution blocks and pixel value within a block is summed up satisfying the threshold value. Check block threshold if it is flame then fire alarm are given. For determining smoke region, block image processing and optical flow technique are used. If network output is smoke then fire alarm is given. It never gives fire alarm for fire like object like car lights or tunnel accident

[3] Fire flame features studies have been conducted for early fire disaster. In addition to fire color, for early fire disaster flame, there are other important characteristics such as irregular shape, increasing area, stable position and so on. So in this paper, these characteristics are discussed, to establish model for fire flame and to propose the fire detection algorithm to improve the accuracy of system. In fire video images the color characteristics as well as the morphological changes are discussed. In this paper, a comprehensive analysis of all the criteria and the algorithm of detecting are proposed, and finally an early fire detection prototype system is designed. After testing, this system has a high accuracy with fast rapid and good robust.

[4] Fuzzy Logic System (FLS) is one that is capable of making real time decisions, even without having all the information about the event. Main focus is to make an intelligent decision using a fuzzy logic system in wireless sensor networks for forest fire detection. Since this technique deals with linguistic variables in a natural way instead of logic variables, it is highly suitable for applications with uncertainties. As fire is not certain so to detect fire Fuzzy Logic System is used. A Fuzzy Logic algorithm is developed using five membership functions as temperature, smoke, light, humidity and distance. Simulation results for the probability of fire based on the fuzzy rules using the status of the membership functions are presented in the paper.

[5] Two models have been developed: one based on predominantly on luminance and the other on chrominance. For the luminance model, concepts from fuzzy logic are used to replace existing heuristic rules and make the classification more robust in effectively discriminating fire and fire like colored objects. Further discrimination between fire and non fire pixels are achieved by a statistically derived chrominance model. The decision for classifying a fire pixel can be made combining the mask derived from fuzzy logic enhanced luminance model with the chrominance model. The model achieves up to $99.00 \%$ correct fire detection rate with a $9.50 \%$ false alarm rate.

[6] Suggests that for automatic fire detection technology multi sensor based fire detection systems are important. But response time of such system is more and it is difficult to use for open space. Fake alarm and fire detection capabilities are two main motives of progress those are still not implemented properly (i.e. timing of fire detection should be quick). In detection system, multiple sensors give a better quality image of the monitored environment which is useful in making alarm decision safe. Multi sensor technology implements enhanced detection systems of fire in desired direction. Also MSBFD algorithm with fire parameters like temperature parameter and smoke density parameter has been presented. Instead of ionization system temperature and smoke sensors were chosen. Due to imposed environmental regulations, difficulties in applying ionized systems have been increased.

\section{Conclusion}

As this complete paper narrate different methodology for fire detection, but none of the methodology are seems to be perfect. Fire detection using only single feature is not more accurate. It generates false alarm for wrong object and sometimes if there is cloudy weather then it is difficult to judge fire object. This paper as bit introduces an idea for fire detection by combing results of different fire features to generate alarm.

\section{References}

[1] Celik, T., Demirel, H., Ozkaramanli, H., Uyguroglu, M., "Fire Detection in Video Sequences Using Statistical Color Model", Proc. Internat. Conf. on Acoustics, Speech, and Signal Processing, vol. 2,no.pp. II-213 - II216, May 2006.

[2] C. Yu, Z. Mei, and X. Zhang, "A real-time video fire flame and smoke detection algorithm," Procedia Engineering, vol. 62, no. 0, pp. 891 - 898, 2013, 9th Asia-Oceania Symposium on Fire Science and Technology.

[3] Chi Jianning, Wu Chengdong, Zhang Yunzhou, "Early fire disaster features research and detection method design in video images", 978-1-4244-6554-5/11/\$26.00 (C) 2011 IEEE

[4] Pouya Bolourchi and Sener Uysal, "Forest Fire Detection in Wireless Sensor Network Using Fuzzy Logic ", 978-0$7695-5042-8 / 13 \quad \$ 26.00 \quad$ (c) $2013 \quad$ IEEE DOI 10.1109/CICSYN.2013.32

[5] T. Celik, H. Ozkaramanli, and H. Demirel, "Fire pixel classification using fuzzy logic and statistical color model," in ICASSP, vol. 1, April 2007, pp. I-1205-I1208

[6] H.C. Muller and A.Fisclier,-Security technology "A Robust Fire Detection Algorithm for Temperature and Optical Smoke Density using Fuzzy Logic", ieeexplore.ieee.org, 1995

\section{Author Profile}

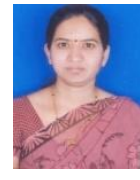

Prof. P.D.Lambhate, received her Degree from WIT, solapur, ME(Comp) from BVCOE Pune, Pursing $\mathrm{PhD}$. In computer Engineering. She is currently working as Professor at Department of Computer and IT , Jayawantrao Sawant College of Engineering, Hadapsar, Pune, India 411028, affiliated to Savitribai Phule Pune University, Pune, Maharashtra, India -411007 . Her area of interest is Data mining, search engine. 


\section{International Journal of Science and Research (IJSR) \\ ISSN (Online): 2319-7064}

Index Copernicus Value (2013): 6.14 | Impact Factor (2014): 5.611

Rohini Jadhav, is currently pursuing M.E (Computer) from Department of Computer Engineering, Jayawantrao Sawant College of Engineering,Pune, India. Savitribai Phule, Pune

University, Pune, Maharashtra,India -411007. She received her B.E. (Computer) Degree from MKSSS Cummins College of Engg. For Women, Savitribai Phule Pune University, Pune, Maharashtra, India - 411007. Her area of interest is Image Processing 